\title{
Incidence of disorders of sexual development in neonates in Ghana: prospective study
}

\author{
Emmanuel Ameyaw ${ }^{1}$ Serwah Bonsu Asafo-Agyei, ${ }^{1}$ leuan A Hughes, ${ }^{2}$ \\ Margaret Zacharin, ${ }^{3}$ Jean-Pierre Chanoine ${ }^{\oplus}$
}

${ }^{1}$ Child Health, KATH, Kumasi, Ghana

${ }^{2}$ Department of Paediatrics, University of Cambridge, Cambridge, UK

${ }^{3}$ Pediatrics, Royal Children's Hospital Melbourne, Parkville, Victoria, Australia

${ }^{4}$ Department of Pediatrics, University of British Columbia, Vancouver, British Columbia, Canada

\section{Correspondence to} Dr Emmanuel Ameyaw, Department of Child Health, Komfo Anokye Teaching Hospital, Kumasi, Ghana ; ekameyaw@yahoo.com

Received 5 February 2019 Revised 29 March 2019

Accepted 31 March 2019 Published Online First 16 May 2019

(C) Author(s) (or their employer(s)) 2019. No commercial re-use. See rights and permissions. Published by BMJ.

To cite: Ameyaw $\mathrm{E}$, AsafoAgyei SB, Hughes IA, et al. Arch Dis Child

2019:104:636-638.

\section{ABSTRACT}

Objective The incidence of disorders of sexual development (DSD) is unknown in sub-Saharan Africa. We describe the characteristics and incidence of DSD in a cohort of infants born in Ghana.

Design Trained research assistants performed systematic genital examination at birth. All infants with suspected abnormal genitalia were further examined by a paediatric endocrinologist.

Setting Komfo Anokye Teaching Hospital, Kumasi, Ghana.

Patients Consecutive infants born in a single centre over a 1-year period (May 2014 to April 2015).

Main outcome measures Incidence of DSD.

Micropenis was defined as a stretched length $<2.1 \mathrm{~cm}$ and clitoromegaly as a clitoral length $>8.6 \mathrm{~mm}$.

Results We examined 9255 infants (93\% of all live births) within 72 hours of birth. Twenty-six neonates had a DSD. Nineteen infants had DSD without genital ambiguity: isolated micropenis $(n=2)$, hypospadias $(n=7)$, cryptorchidism $(n=4)$ and clitoromegaly $(n=6)$. Seven infants had DSD with ambiguity: clitoromegaly with a uterus on ultrasound and elevated 17-hydoxyprogesterone, suggesting XX DSD due to congenital adrenal hyperplasia $(C A H)(n=4)$ and micropenis, hypospadias and gonads in a bifid scrotum or in the inguinal region, consistent with XY DSD $(n=3)$. Conclusion The incidence of atypical genitalia was $28 / 10,000$ (95\% Cl 17/10 000 to 39/10 000) live births. The incidence of CAH was $4.3 / 10000(95 \% \mathrm{Cl} 1.2 / 10$ 000 to $11.1 / 10000$ ) and was strongly associated with consanguinity.

\section{INTRODUCTION}

Disorders of sexual development (DSDs) are congenital anomalies in which development of chromosomal, gonadal or anatomical sex is atypical. ${ }^{1}$ Delivery of such a neonate understandably causes psychological stress to the family. Additionally, in congenital adrenal hyperplasia $(\mathrm{CAH})$, the most common form of DSD, salt wasting can be present, leading to severe dehydration, shock and eventually death.

Investigations leading to a specific diagnosis of the various DSDs can be complex and expensive. However, in addition to careful physical examination of the external genitalia, investigations that lead to an informed discussion about sex assignment (imaging of internal genitalia with either genitogram or ultrasound, determination of serum 17-hydroxyprogesterone) can be requested in tertiary care centres in Ghana. Karyotype and more

\section{What is already known on this topic?}

- Awareness of disorders of sexual development in low-income settings is poor and diagnosis and management are challenging.

\section{What this study adds?}

- When neonatal examination of genitalia is systematically performed in Ghana, disorders of sexual development (DSDs) are not uncommon.

- DSD can be recognised early and an informed decision about sex assignment can be performed taking into account the specificities of the African society despite suboptimal availability of diagnostic procedures.

- In the absence of hydrocortisone and fludrocortisone, the outcome of patients with congenital adrenal hyperplasia is poor in lowincome settings.

sophisticated genetic tests and hormone assays are not routinely available.

In the Ashanti region of Ghana where our study was performed, the predominant Asante ethnic group has a matrilineal kinship system. ${ }^{2}$ An expectant Asante mother often comes to the hospital with several female family members (aunt, mother and/or grandmother), while the father joins them less often. Although the role of the mother's family is decreasing in modern society, these extended family members still play an important role in decision making in childcare. Ideally, in Africa, as elsewhere, sex assignment and naming should be deferred until the appropriate stakeholders (medical team, the family and sometimes community leaders) have discussed sufficient information to assign a sex that will ensure acceptance of the infant by the family and the community.

The aim of this study was to determine the incidence of DSD in a cohort of infants born in a teaching hospital in Ghana and to describe the clinical characteristics of infants born with genital abnormalities.

\section{METHODS}

Study design and participants

Four trained research assistants prospectively performed systematic examination of the external genitalia in live neonates delivered at Komfo Anokye 
Teaching Hospital (KATH), Kumasi, Ghana, between May 2014 and April 2015. Infants where there was concern about atypical genitalia were further examined by a paediatric endocrinologist.

The examination included identification of genital anomalies such as micropenis (defined as a stretched length $<2.1 \mathrm{~cm}$ ), ${ }^{3}$ clitoromegaly (defined as a clitoral length $>8.6 \mathrm{~mm}$ ), ${ }^{4}$ presence of hypospadias, labioscrotal fusion and presence of gonads in inguinal or scrotal folds.

Pelvic ultrasound was performed in all neonates who presented with atypical genitalia to determine the presence of uterus or cervix or of testes in the inguinal region or abdomen. Serum17-hydroxyprogesterone was determined by high-performance liquid chromatography (MDS-Lancet Laboratories, Ghana) when a uterus was identified on ultrasound.

\section{Statistical analysis}

Demographic data including age, sex, birth weight, gestation and genital characteristics were collected, entered onto an Epi-info software V.3.5.1 and transferred onto Stata statistical software V.12.1 for data analysis. Continuous variables were summarised and presented as frequency $(95 \%$ CI). The relationship between consanguinity and genital abnormalities was assessed by $\chi^{2}$. A $p$ value of $<0.05$ was considered statistically significant. The study was approved by the Committee on Human Research, Publications and Ethics of Kwame Nkrumah University of Science and Technology, Kumasi (Reference: $\mathrm{CHRPE} / \mathrm{AP} / 127 / 14)$. Informed consent was obtained for each participant before recruitment.

\section{RESULTS}

Study sample

A total of 10337 infants (9948 live births and 389 stillbirths) were delivered at KATH over the 12-month period of the study. We examined 9255 infants ( $93 \%$ of all live births) within 72 hours of birth. Most examinations were carried out within the first day of life. Because of early discharge, 693 infants $(=7 \%)$ left the hospital before they could be examined. All parents agreed to be included in the study.

\section{Disorders of sexual development}

Normal genitalia were identified in $4430(=48 \%)$ female and $4799(=52 \%)$ male infants. Twenty-six full-term infants had some form of DSD.

Nineteen out of these 26 infants had DSD without genital ambiguity. Four had isolated unilateral $(\mathrm{n}=2)$ and bilateral $(\mathrm{n}=2)$ cryptorchidism with testes present at echography in all infants, seven had isolated hypospadias and two had isolated micropenis. All were designated male. Six had isolated clitoromegaly, a uterus present on ultrasound and were designated female.

Seven of the 26 had DSD with genital ambiguity. Their characteristics are described in table 1 . Four had an enlarged clitoris, labioscrotal folds, no palpable gonads, a uterus present on ultrasound and elevated levels of serum 17-hydroxyprogesterone, consistent with a diagnosis of CAH. Three infants had micropenis, hypospadias and gonads palpated in a bifid scrotum or in the inguinal region, suggesting a form of XY DSD.

Among the 9255 infants examined, $62(0.67 \%)$ were born to known consanguineous families These included three of the four infants with $\mathrm{CAH}$ and two of the three infants with male DSD.

The incidence of DSD in this study was thus 28/10 000 (95\% CI 17/10 000 to 39/10 000) live births. The incidence of CAH was 4.3/10 000 (95\% CI 1.2/10 000 to 11.1/10 000) live births and was strongly associated with consanguinity $(\mathrm{p}<0.00001)$.

\section{Management}

Three infants with isolated cryptorchidism had spontaneous testicular descent within 22 months. One infant with bilateral cryptorchidism (lower abdomen) had unilateral orchidopexy at 2 years of age because one of the testes failed to descent spontaneously. Infants with isolated hypospadias were referred for corrective surgery. Those with isolated micropenis had normal pituitary function. They were given a total of three intramuscular injections of $25 \mathrm{mg}$ of a mixture of testosterone esters (isocaproate, phenylpropionate, propionate and decanoate) at monthly intervals.

The four infants with CAH were treated with prednisolone, hydrocortisone and fludrocortisone being unavailable in Ghana at the time of diagnosis. Salt supplementation was provided. Three out of four infants with CAH have died at home. The exact cause

Table 1 Clinical, echographic and laboratory characteristics of individual neonates with DSD and genital ambiguity

\begin{tabular}{|c|c|c|c|c|c|c|c|c|c|c|c|}
\hline \multirow[b]{2}{*}{ DSD type } & \multirow[b]{2}{*}{ Consanguinity } & \multicolumn{7}{|c|}{ Physical characteristics } & \multicolumn{3}{|c|}{ Investigations } \\
\hline & & $\begin{array}{l}\text { Labioscrotal } \\
\text { features }\end{array}$ & Hypospadias & Prepuce & Gonads & Chordae & $\begin{array}{l}\text { Phallic } \\
\text { features }\end{array}$ & $\begin{array}{l}\text { Prader } \\
\text { stage }\end{array}$ & $\begin{array}{l}\text { Abdominal } \\
\text { /inguinal } \\
\text { ultrasound }\end{array}$ & $\begin{array}{l}17 \text { OHP } \\
\text { (nmol/L) }\end{array}$ & Electrolytes \\
\hline CAH 1 & Yes & Partially fused & No & - & No & No & $\begin{array}{l}\text { Enlarged } \\
\text { clitoris }\end{array}$ & P2 & Uterus & 144 & Normal \\
\hline $\mathrm{CAH} 2$ & Yes & Partially fused & No & - & No & No & $\begin{array}{l}\text { Enlarged } \\
\text { clitoris }\end{array}$ & P2 & Uterus & 247 & Normal \\
\hline $\mathrm{CAH} 3$ & No & Partially fused & No & - & No & No & $\begin{array}{l}\text { Enlarged } \\
\text { clitoris }\end{array}$ & P2 & Uterus & 505 & $\begin{array}{l}\text { Hyperkalaemia } \\
\text { /hyponatraemia }\end{array}$ \\
\hline $\mathrm{CAH} 4$ & Yes & $\begin{array}{l}\text { Completely } \\
\text { fused }\end{array}$ & No & - & No & No & $\begin{array}{l}\text { Enlarged } \\
\text { clitoris }\end{array}$ & P5 & Uterus & 546 & $\begin{array}{l}\text { Hyperkalaemia } \\
\text { /hyponatraemia }\end{array}$ \\
\hline $\begin{array}{l}\text { Male } \\
\text { DSD } 1\end{array}$ & Yes & Bifid scrotum & Yes & Abnormal & $\begin{array}{l}\text { R testis: } \\
\text { intraabdominal } \\
\text { L testis: } \\
\text { hemiscrotum }\end{array}$ & Yes & Micropenis & ND & Testes & ND & Normal \\
\hline Male DSD 2 & No & $\begin{array}{l}\text { Hypoplastic } \\
\text { scrotum }\end{array}$ & Yes & Abnormal & $\begin{array}{l}\text { Both in inguinal } \\
\text { region }\end{array}$ & Yes & Micropenis & ND & Testes & ND & Normal \\
\hline Male DSD 3 & Yes & Bifid scrotum & Yes & Abnormal & $\begin{array}{l}\text { R testis: } \\
\text { hemiscrotum } \\
\text { L testis: } \\
\text { intraabdominal }\end{array}$ & No & Micropenis & ND & Testes & ND & Normal \\
\hline
\end{tabular}

Normal range for 170HP (nmol/L): Premature infants: $0.8-17.0$; term infants: $0.2-2.3$, prepubertal children: $0.1-2.7$

DSD, disorder of sexual development; ND, not done. 
of death is unknown. The three with male DSD were given a total of three intramuscular injections of $25 \mathrm{mg}$ of a mixture of testosterone esters at monthly intervals to enlarge the phallus prior to hypospadias repair and concomitant orchidopexy. They are being raised as males.

\section{DISCUSSION}

This study is to our knowledge the first to provide an estimate of DSD incidence in infants born in sub-Saharan Africa. Our work highlights the major difficulties faced by the health professionals while caring for these patients. However, it also shows that DSD can be recognised early and that an informed decision about sex assignment, arguably the most important issue for the patient and the family, can be performed taking into account the specificities of the African society despite limited resources.

In Ghana, similar to many African countries, genital examination is not routinely performed at birth. Most of the deliveries are performed by midwives who are not trained to perform a detailed neonatal examination. In addition, it is estimated that a quarter of the deliveries still take place at home. This is important because in traditional Ashanti culture, the infant is only presented to the community at the age of 6 weeks. As a consequence, DSDs are rarely noted at birth, which leads to delayed diagnosis and management of DSDs. However, over the past 10 years, capacity in paediatric endocrinology has increased markedly in sub-Saharan Africa thanks to the Paediatric Endocrinology Training Centres for Africa. ${ }^{5}$ This has led to earlier recognition and better management of patients with paediatric endocrine conditions and to improved education of health professionals, including midwives. ${ }^{56}$

Presently, thanks to the increasing expertise in paediatric endocrinology, it is encouraging to see that the limited biochemical, hormonal and radiological investigations that are available make it possible to help the family make an informed decision on the sex of rearing. Funding for additional key investigations, such as a karyotype, should be considered to further improve the aetiological diagnosis of DSD in resource-limited settings.

Unfortunately, essential medicines such as hydrocortisone and fludrocortisone were mostly unavailable despite being included in WHO model list of essential medicines. ${ }^{7}$ This highlights the need to adapt the therapeutic guidelines, usually written for and by health professionals working in high-resource settings, to low-resource settings. ${ }^{6}$ In high-resource settings where fludrocortisone is usually available, salt supplementation is recommended until weaning but is not routinely offered. ${ }^{8} 9$ In low-resource settings, when fludrocortisone is not available, the need for salt supplementation should be emphasised to compensate for salt wasting.

We identified seven neonates with ambiguous genitalia. Four of these presumably had $\mathrm{CAH}$, corresponding to an incidence of 4.3/10 000 live birth. This is higher than what has been reported in other countries such as the UK (incidence $0.67 / 10$ 000). ${ }^{10}$ However, not surprisingly, countries where consanguinity is common such as Egypt (overall consanguinity $21 \%$ to $33 \%)^{11}$ have reported higher incidences of this recessive condition $(10 / 10000$ neonates). ${ }^{12}$ Consanguinity is not widespread in Ghana but three of the four patients diagnosed as $\mathrm{CAH}$ belonged to consanguineous families (Table).

Our study has several strengths. First, it is the first in sub-Saharan Africa to provide incidence data. A recent South African retrospective study described the characteristics of a large population of children with DSD but did not provide incidence data. ${ }^{13}$ Second, it is a prospective study where more than $90 \%$ of all consecutive infants born in one academic centre were examined. Third, all infants with DSD were examined by one of two paediatric endocrinologists.

\section{CONCLUSION}

We found an incidence of DSD in Ghana of 28/10 000 (95\% CI $17 / 10000$ to $39 / 10000$ ) live births. Our study highlights the fact that in resource-limited settings, better DSD care requires the implementation of routine neonatal genital examination by health professionals (including midwives), sufficient capacity in paediatric endocrinology, timely access to diagnostic tests to clarify the aetiology of DSD and increased availability of essential medicines.

Acknowledgements We are grateful to Professor Henry Opare-Addo, Head of Department of Obstetrics and Gynaecology, KATH for supporting the project. The study could not have been performed without Kwabena Boateng, Eunice Boateng, Ophelia Kyeremeh and Alice Adoma Agyei who performed the examination of the external genitalia in the neonates.

Contributors EA was the principal investigator, contributed to the concept, the study design, conducted the study, drafted the manuscript and contributed to review. SBAA assisted in conduct of the study, contributed to manuscript writing and review. IAH contributed to writing and review of paper. MRZ contributed to the concept and study design, contributed to the manuscript and review. JPC conceived the concept and contributed to study design, contributed to the manuscript writing and review.

Funding Global Pediatric Endocrinology and Diabetes (GPED, www.globalpedendo. org) funded this project.

Disclaimer The funders had no role in the collection, analysis and interpretation of data or the writing of this manuscript.

Competing interests None declared.

Patient consent for publication Not required.

Provenance and peer review Not commissioned; externally peer reviewed.

Data sharing statement All deidentified data were made available to all coauthors by the first author.

\section{REFERENCES}

1 Hughes IA, Houk C, Ahmed SF, et al. Consensus statement on management of intersex disorders. Arch Dis Child 2006;91:554-63.

2 Shin M. What does it means to be a family man in a matrilineal society? Ghana: Masculinity and women's empowerment in Akan, 2016.

3 Asafo-Agyei SB, Ameyaw E, Chanoine JP, et al. Normative penile anthropometry in term newborns in Kumasi, Ghana: a cross-sectional prospective study. Int J Pediatr Endocrinol 2017;2017:2.

4 Asafo-Agyei SB, Ameyaw E, Chanoine JP, et al. Clitoral size in term newborns in Kumasi, Ghana. Int J Pediatr Endocrinol 2017;2017:6.

5 Odundo GO, Ngwiri T, Otuoma 0, et al. The Impact and Successes of a Paediatric Endocrinology Fellowship Program in Africa. Int J Endocrinol 2016;2016:1-6.

6 Zacharin M, Chanoine JP, Cassorla F, et al. Promoting excellence in the care of pediatric endocrine diseases in the developing world. Pediatrics 2013;131:e57 $3-e 578$

7 Rowlands A, Ameyaw E, Rutagarama F, et al. Insights from the WHO and National Lists of Essential Medicines: Focus on Pediatric Diabetes Care in Africa. Horm Res Paediatr 2018;90:82-92.

8 Hughes IA. Management of congenital adrenal hyperplasia. Arch Dis Child 1988;63:1399-404.

9 Bonfig W, Roehl F, Riedl S, et al. Sodium Chloride Supplementation Is Not Routinely Performed in the Majority of German and Austrian Infants with Classic SaltWasting Congenital Adrenal Hyperplasia and Has No Effect on Linear Growth and Hydrocortisone or Fludrocortisone Dose. Horm Res Paediatr 2018;89:7-12.

10 Khalid JM, Oerton JM, Dezateux C, et al. Incidence and clinical features of congenital adrenal hyperplasia in Great Britain. Arch Dis Child 2012;97:101-6.

11 Tadmouri GO, Nair P, Obeid T, et al. Consanguinity and reproductive health among Arabs. Reprod Health 2009;6:17.

12 Tayel SM, Ismael H, Kandil H, et al. Congenital adrenal hyperplasia in Alexandria, Egypt: a high prevalence justifying the need for a community-based newborn screening program. J Trop Pediatr 2011;57:232-4.

13 Ganie Y, Aldous C, Balakrishna Y, et al. Disorders of sex development in children in KwaZulu-Natal Durban South Africa: 20-year experience in a tertiary centre. J Pediatr Endocrinol Metab 2017;30:11-18. 